\title{
LEVEDURAS DE Paracoccidioides brasiliensis SUBMETIDAS À PRIVAÇÃo DE GLICOSE OU NITROGÊNIO EXIBEM VACÚOLOS AUTOFÁGICOS
}

\author{
Giselle Ferreira Ribeiro' \\ Flavia Villaça Morais ${ }^{2}$
}

Resumo: O Paracoccidioides sp. é o agente etiológico da paracoccidioidomicose, uma micose sistêmica adquirida por inalação de conídios do fungo que, quando se instalam nos pulmões e transitam para a forma leveduriforme, podem causar a doença. Durante o parasitismo, essas leveduras são submetidas a estresse nutricional. A autofagia, evento importante para adaptação das células às condições de estresse, pode ser um dos mecanismos regulatórios envolvidos na sobrevivência deste fungo dentro do hospedeiro. O objetivo deste trabalho foi avaliar a viabilidade celular, a morfologia e a presença de vacúolos autofágicos em leveduras do isolado 18 de $P$. brasiliensis, submetidas à estresse nutricional. Após $2 h$ de incubação nos diferentes meios, foi possível observar marcações, por monodansilcadaverina (MDC), sugerindo presença de vacúolos autofágicos. A privação de nitrogênio promoveu após $48 \mathrm{~h}$ a inviabilidade celular e o aumento no tamanho celular e no número de brotos. A privação de glicose provocou a inviabilidade celular após $120 h$, porém, não apresentou alterações morfológicas.

Palavras-chave: Paracoccidioides sp.; Autofagia; Privação.

\footnotetext{
1 Pós-Graduação em Ciências Biológicas/Instituto de Pesquisa e Desenvolvimento/Universidade do Vale do Paraíba, Brasil. E-mail: giselle_ferreira13@hotmail.com.

2 Pós-Graduação em Ciências Biológicas/Instituto de Pesquisa e Desenvolvimento/Universidade do Vale do Paraíba, Brasil. E-mail: flavia@univap.br.
} 